\title{
A cidade sob vigilância: Maringá (PR) nos arquivos da Delegacia de Ordem Política e Social (Dops) do Paraná (1947-1981)
}

\section{The city under surveillance: Maringá (PR) in the registers of the Political and Social Order Department (Dops) of the state of Paraná, Brazil (1947-1981)}

\author{
Reginaldo Benedito Dias*
}

\begin{abstract}
Resumo
No início da década de 1990, o estado do Paraná foi pioneiro na abertura dos arquivos da Delegacia de Ordem e Política e Social (Dops) à consulta pública, iniciativa que contribuiu para a sedimentação de um campo de pesquisas acadêmicas sobre temas relacionados e subsidiou o avanço de lutas pelos direitos humanos. 0 presente artigo tem o objetivo a investigar e interpretar como os movimentos e agentes políticos da cidade de Maringá (PR) foram vigiados pela Dops e registrados em seus arquivos. Como regra, a delegacia tinha seu trabalho direcionado pela natureza das atividades e não pela base espacial, mas o mapeamento de suas ações em um dado território é revelador da trama política ali vivida e da incidência das atividades dos órgãos de segurança em sua dinâmica política. A investigação abarca o período de 1947 ao início da década de 1980, vale dizer, da fundação de Maringá até a desativação da delegacia. $O$ acervo é eclético e permite diversas incursões, mas a análise priorizou as incidências mais representativas sobre movimentos sociais e atividades de partidos e agrupamentos de esquerda, seguindo as prioridades da Dops.
\end{abstract}

Palavras-chave: Delegacia de Ordem Política e Social; Maringá (PR); movimentos políticos de esquerda; repressão, ditadura.

\begin{abstract}
The state of Paraná opened the registers of the Political and Social Order Department (DOPS) for public consultation in the early 1990s. The initiative contributed towards the establishment of a field of academic research on themes related to the struggle for human rights. This paper investigates and interprets how the political movements and agents of the city of Maringá
\end{abstract}

\footnotetext{
*Doutor em História pela UNESP. Professor do Departamento e da Pós-Graduação em História da UEM. E-mail: reginaldodias13@gmail.com
} 
PR Brazil were spied upon by the DOPS and their activities reported in their registers. As a rule, the special police department focused on activities and was not specifically concerned with the physical bases. However, mapping of their activities within a certain territory reveals the political plot experienced in the place and the occurrence of activities of security organs within their political dynamics. Current investigation ranges between 1947 and the early 1980s, or rather, from the establishment of Maringá to the deactivation of the department. The archives are highly eclectic but analyses gave priority to the most representative occurrences on social movements, party politics and leftist groupings, following the DOPS's priorities.

Keywords: Political and Social Order Department; Maringá, Brazil; political movements of the Left; repression; dictatorship.

\section{Preâmbulo}

Em 1991, por meio do Decreto 577, o governo do Paraná determinou a transferência dos documentos da Delegacia de Ordem Política e Social (Dops) ao Arquivo Público estadual e disponibilizou o acervo à consulta pública. Estabelecida na conjuntura imediatamente posterior ao fim da ditadura instaurada em 1964 e da promulgação da Constituição de 1988, tratava-se de medida pioneira de liberação dos arquivos da repressão. A iniciativa contribuiu para o avanço de lutas pelos direitos humanos e subsidiou a sedimentação de pesquisas acadêmicas sobre temas relacionados.

Ao desenvolver pesquisas sobre movimentos políticos ocorridos no período da ditadura de 1964, o autor deste texto teve seu interesse despertado para a possibilidade de realizar um mapeamento dos registros relacionados à cidade de Maringá (PR), consideradas as mais diversas manifestações que estiveram no campo de interesse da DOPS. Como regra, a delegacia tinha seu trabalho direcionado pela natureza das atividades e não pela base espacial, mas o mapeamento de suas ações em um dado território é revelador da trama política ali vivida e da incidência das atividades dos órgãos de segurança em sua dinâmica.

Inicialmente, o objetivo era investigar os anos vividos sob a ditadura de 1964, mas o levantamento documental estimulou a promover um recuo cronológico e incorporar o período anterior, no qual a DOPS, embora o país vivesse sob uma Constituição democrática, encontrava-se ativa. Assim, a análise 
estende-se da origem de Maringá, fundada em 1947, até os últimos registros disponíveis nos arquivos, datados do início da década de 1980.

O denominador comum entre os dois períodos, malgrado as diferenças de ordenamento jurídico e político do país, era a lógica da suspeição contra atividades supostamente atentatórias à segurança nacional, inspirada no imaginário da Guerra Fria. ${ }^{1} \mathrm{O}$ acervo é eclético e permite diversas incursões, mas o objetivo desta investigação foi analisar as incidências mais representativas sobre movimentos sociais e atividades de partidos e agrupamentos de esquerda, seguindo as prioridades da DOPS.

O amplo arquivo é constituído, principalmente, de pastas temáticas e de fichas individuais. Para a sistematização e interpretação dos dados, a opção preferencial foi pelas pastas temáticas. Informações contidas nas fichas individuais foram incorporadas, subsidiariamente, para dialogar com a narrativa contida naquelas pastas. Foi adotada uma postura de discrição na utilização dos nomes dos envolvidos. Foram citados apenas nomes em casos específicos, quando se tratava de pessoas que mantiveram publicamente uma identidade com seu engajamento naquela conjuntura.

\section{A vigilância nos anos de origem e de formação do município}

Para compreensão do mapa do território de vigilância relacionado a Maringá, é necessário abordar, ainda que resumidamente, dados da origem e da estruturação da vida política do município, criado pela Lei Estadual 790/51 e implantado em dezembro de 1952, quando tomaram posse os primeiros dirigentes eleitos, prefeito e vereadores. Uma periodização rigorosa remete, entretanto, a três fases imediatamente anteriores.

A primeira fase data de 1938, quando a empresa colonizadora, a Companhia de Terras do Norte do Paraná, iniciou as vendas dos lotes rurais do que viria ser o território do município. A segunda fase foi aberta em 1942 com a fundação do núcleo urbano pioneiro, referido na memória local como "Maringá Velho". Até então, o povoado fazia parte da jurisdição administrativa de Londrina. A terceira fase foi deflagrada em 10 de maio de 1947, quando a empresa colonizadora, consolidado o planejamento prévio, iniciou a venda dos lotes da área urbana definitiva. Na tradição, essa data foi entronizada como o marco da fundação da cidade. A circunscrição municipal nesse momento era Apucarana. Logo em seguida, ainda em 1947, Maringá tornou-se

\footnotetext{
${ }_{1}^{1}$ MAGALHÃES, Marionilde D. B. Dops: a lógica da suspeição. In Revista Brasileira de História. Vol. 17, nº. 34, 1997, p.203-221.
} 
distrito do recém-fundado município de Mandaguari, vínculo mantido até a Lei 790/1951. ${ }^{2}$

Os primeiros anos dessa periodização prévia coincidem com a ditadura do Estado Novo, mas a fundação oficial de Maringá e a implantação do município já ocorrem no período democrático, vivido sob a égide da Constituição de 1946. Embora o planejamento da empresa colonizadora estabelecesse o objetivo de Maringá ser polo de uma vasta região, tratava-se, na época da emancipação, de um núcleo municipal promissor, mas ainda incipiente. Tornou-se sede de Comarca em março de 1954, pouco mais de um ano após a posse de prefeito e vereadores. Nesses primórdios, a estrutura policial de Maringá era precária, mas havia, em âmbito estadual, pressão por reformas do sistema visando ao controle mais efetivo nas regiões que se encontravam em desenvolvimento. ${ }^{3}$

A sedimentação das atividades políticas institucionais pode ser conferida pela participação nas eleições municipais de 1947, quando a população do distrito de Maringá elegeu representantes para a Câmara de Vereadores de Mandaguari, fato repetido em 1951. Nesse período, as principais legendas que caracterizariam o sistema partidário se vertebravam no município.

Para focalizar as atividades priorizadas pela vigilância exercida pela DOPS, adicione-se que há vestígios da presença do Partido Comunista do Brasil (PCB) em Maringá desde 1947, ano oficial de fundação da cidade, conforme depoimento do Sr. Gregório Parandiuck a um livro do jornalista Milton Heller: "em 1947, vim para Maringá e logo fiz contato com o Manoel Jacinto. Começamos a organizar células do partido em Paiçandu, Estrada Fartura, Estrada Bandeirantes e outras. Quase não existiam cidades no Norte do Paraná". ${ }^{4}$

Se a fundação oficial de Maringá ocorreu no período democrático, constata-se, todavia, que o ano de 1947 é caracterizado, nacionalmente, pelo fim da curta fase de atuação legalizada do PCB, iniciada em 1945. De maneira mais ampla, é o começo da chamada "Guerra Fria". Os primeiros apontamentos da DOPS relacionados ao território de Maringá focalizavam os comunistas, fosse

\footnotetext{
${ }^{2}$ LUZ, France. Maringá: o fenômeno urbano em uma zona pioneira. Maringá: Prefeitura Municipal, 1997. ${ }^{3}$ ALMEIDA, Vivian F. de Carvalho. Policiamento e sociedade em Maringá (1948-64). Maringá: Dissertação de mestrado em História. PPH-UEM. 2012, p. 79.

${ }^{4}$ HELLER, Milton I. Resistência democrática. A repressão no Paraná. Rio de Janeiro: Paz e Terra; Curitiba: Secretaria da Cultura do Paraná, 1988, p. 540. Gregório Parandiuck viria a ser detido em 1975, no contexto da "Operação Marumbi". A ficha individual disponível nos arquivos da DOPS limita-se a esse registro. Manoel Jacinto era um destacado dirigente do PCB em Londrina.
} 
para o mapeamento dos nomes de aficionados, fosse para a identificação de atividades.

No contexto do estado do Paraná, o PCB obteve registro legal em 14 de julho de 1945. Apresentou candidatos nas eleições de 1945 e também ao pleito realizado em janeiro de 1947. Na segunda vez, obteve êxito na eleição de um deputado estadual. De volta à clandestinidade, lançaria candidatos por meio das legendas legalizadas, obtendo a eleição de vereadores em alguns municípios. No plano organizacional, de acordo com Kieller e Codato, havia a seguinte territorialização:

No final da década de 1940, em função das distâncias geográficas e das dificuldades de comunicação entre as regiões do estado, os comunistas paranaenses tinham construído duas estruturas de direção intermediárias, além de outra estadual centralizada. As estruturas intermediárias eram o Comitê Distrital 1 e 2 (CD1 e CD2), uma responsável pelas atividades comunistas no norte do Estado, e a outra no sul, a partir de Curitiba. Isso causava problemas operacionais para a organização, porque o contato com a direção do norte se dava mais frequentemente com São Paulo do que com o diretório regional do partido. ${ }^{5}$

Kieller e Codato, detalhando a implantação regional no período posterior a 1950, asseveram que o PCB estava presente nas cidades mais importantes do estado: "Londrina, Maringá, Ponta Grossa, Curitiba, Ibiporã, União da Vitória, Rio Negro, Cornélio Procópio, Cambé, Sertanópolis, Antonina, Paranaguá, Marrecas (depois Francisco Beltrão), Jaguapitã, Morretes e Curiúva" 6 . O Norte do estado está bem representado, sobretudo a área polarizada por Londrina, sede do comitê distrital.

Na região "Norte pioneiro", o PCB havia sido protagonista do levante dos posseiros em Porecatu, ocorrido no final da década de 1940 e início da seguinte. ${ }^{7}$ No apoio a esse movimento, o partido articulou uma organização denominada "Liga Camponesa" em algumas localidades da grande região. Segundo depoimento de um dos personagens do movimento de Porecatu, uma delas estaria sediada em Maringá. ${ }^{8}$

\footnotetext{
${ }^{5}$ KIELLER, M; CODATO, A. A elite dos comunistas e a sua história no Paraná. In CODATO, A; KIELLER, M. Velhos Vermelhos. História e memória dos dirigentes comunistas no Paraná. Curitiba: UFPR, 2008, p. 50.

${ }^{6}$ Ibidem, p. 53.

${ }^{7}$ PRIORI, Angelo. O levante dos posseiros: a revolta camponesa de Porecatu e a ação do Partido Comunista Brasileiro no campo. Maringá: Eduem, 2011.

${ }^{8}$ Essas experiências precedem as Ligas Camponesas do Nordeste, que tiveram origem política diversa e características específicas. IPOLITO, V. É permitido proibir: o Dops e a repressão aos comunistas no Norte do Paraná. (1945-53). Dissertação de mestrado em História. Maringá: PPH-UEM, 2009, p. 153.
} 
Maringá teria importância crescente, à medida que confirmava sua vocação de polo regional. Na pasta "PCB-relações nominais", a DOPS sistematizou várias listagens de pessoas que, supostamente, fariam parte do partido comunista. Na lista de 1951, não há a inclusão específica da localidade de Maringá. Em compensação, há uma expressiva lista atribuída ao município de Mandaguari, da qual constavam 29 nomes. Para comparação, a lista de Londrina continha 40 nomes. É possível que algumas pessoas citadas na lista de Mandaguari habitassem o distrito de Maringá. Constata-se pelo menos um nome que seria identificado como dirigente comunista em Maringá e seria processado em 1964: Gregório Sepúlveda. Na mesma pasta, encontra-se uma relação, datada de 24 de maio de 1956, com nomes de 42 pessoas que fariam parte do PCB em Maringá e que ainda não constavam do fichário.

Não é o caso de reproduzir acriticamente esses dados, visto que os critérios da polícia política, regidos pela lógica da Guerra Fria, tendiam a ser muito elásticos, mas a variação dos números em poucos anos, considerados os parâmetros do órgão de vigilância, não deixa de ser expressiva. De resto, há outros indicadores que ampliam a compreensão sobre o processo.

Em 1956, o PCB de Maringá lançou um candidato a vereador por uma legenda legal, o comerciante e contabilista Bonifácio Martins, e obteve sucesso na conquista da cadeira. Martins mudara-se havia pouco tempo para Maringá, logo após se casar, para reiniciar a vida na região recentemente colonizada. Havia sido ativista político na fase de legalização do PCB, no interior de São Paulo, e atuara no movimento estudantil. Não viera para Maringá com objetivos políticos, mas foi surpreendido com uma ilustre visita. Atuando clandestinamente na região, o lendário dirigente pecebista Gregório Bezerra o procurou e lhe propôs que fosse candidato, assegurando que seu pouco tempo na cidade não era impedimento: "garanto que você se elege. Pode deixar que temos gente que mora no campo". 9

Na ficha que a DOPS do Paraná dedicou a Bezerra, em linguagem vazada pelo imaginário da Guerra Fria, consta que ele teria sido "enviado pelo Kremlin" para a recuperação do setentrião paranaense. Afirma que o fichado havia sido responsável "pelas primeiras organizações de base do PC em Maringá, em 1954”. Em livro de memórias, Bezerra narra o seu deslocamento para Maringá, ocorrido em 1954: "instalei-me no centro de uma rica região

${ }^{9}$ Cf. MARTINS, Bonifácio. Entrevista. Concedida à Divisão de Patrimônio Histórico de Maringá. 1995. 
agrícola: Alto Paraná, Paranavaí, Peabiru, Campo Mourão, Cascavel, Toledo, Engenheiro Beltrão, Mamborê, Cianorte, Terra Nova". ${ }^{10}$

O livro de memórias mapeia contatos e relações políticas em cidades do Norte e do Oeste do Paraná, salientando a arregimentação sindical em favor dos trabalhadores rurais. Não comenta, contudo, a articulação eleitoral para a Câmara de Vereadores de Maringá, mas não há motivo para colocar em dúvida o depoimento de Bonifácio Martins. Como baliza cronológica, Bezerra narra que teve de se retirar do Paraná após a eleição para presidente da República e governador de 1955, pois foi denunciado pelo Senador Othon Mader, da UDN, candidato derrotado à chefia do Executivo estadual.

A previsão das possibilidades do candidato lançado ao pleito municipal de Maringá em 1956 mostrou-se correta. Inscrito no Partido Republicano (PR), Bonifácio Martins foi eleito com 167 votos. ${ }^{11}$ Como não havia vínculos políticos profundos com o PR, não resta dúvida de que a arregimentação de votos em favor de Bonifácio Martins, novato em Maringá, foi garantida pela organização clandestina do PCB.

Duas pastas da DOPS, intituladas "Delegacia de Polícia de Maringá", reúnem, presumivelmente, as principais ocorrências que despertaram, nas décadas de 1950 e 1960, a atenção da autoridade policial local. As pastas são compostas de forma razoavelmente assistemática, mas servem de amostra das atividades da delegacia local como instância subsidiária da polícia política especializada.

Em 1953, circulou um panfleto intitulado "Campanha Nacional pró Imprensa Popular”. Aparentemente, era produzido pela direção nacional do PCB, subscrito por intelectuais e artistas de expressão em todo o país e reproduzido pelos militantes locais. Em tom de oposição dura a Getúlio Vargas, promovia denúncias e clamava apoio para a criação de um "jornal do povo, arma de luta do próprio povo". Os divulgadores locais do material alegaram que esse jornal já existia, mas sobrevivia com dificuldades, exatamente por sua independência. Tratar-se-ia do jornal de Luiz Carlos Prestes. Afirmavam que era um dever patriótico a organização de uma comissão de "Ajuda da imprensa popular" no município e de subcomissões nos distritos, no campo e na cidade. ${ }^{12}$

\footnotetext{
${ }^{10}$ BEZERRA, Gregório. Memórias. São Paulo: Boitempo, 2011, p.466.

${ }^{11}$ DIAS, R.B. Da arte de votar e ser votado. Maringá: Clichetec, 2008.

${ }^{12}$ Pasta “Delegacia de Polícia de Maringá”.
} 
O fato foi denunciado, por meio de rádio telegrama, pelo delegado de Maringá ao delegado especializado do órgão estadual, do qual constam nomes de cinco cidadãos, supostos responsáveis por uma comissão organizadora da campanha na região. A pasta não contém considerações das autoridades policiais. ${ }^{13}$

Em 2 de junho de 1954, o delegado de polícia local comunicou à DOPS uma ocorrência e pediu esclarecimentos sobre procedimentos. Nas duas pastas citadas, trata-se do primeiro documento assinado pela autoridade policial local. Eis os dizeres:

Com o presente encaminho a Vs. Um número do jornal diário "A hora", que se edita nesta cidade, desta data, que em uma seção livre, publicou o "Projeto de Programa do Partido Comunista do Brasil", ilustrada com a fotografia de Luiz Carlos Prestes. A finalidade da presente comunicação é para cientificar a essa Especializada, sobre atividades submersivas (sic) dos elementos do extinto partido comunista, aqui residentes, em número bastante apreciável, e, para solicitar de V.S. informações sobre as medidas que devem ser tomadas. ${ }^{14}$

A edição do jornal tinha a data de 2 de junho de 1954. Na página que veicula o projeto de programa do $\mathrm{PCB}$, lê-se que o documento, firmado pelo Comitê Central em dezembro de 1953 para ser aprovado no IV Congresso, havia sido transcrito da "Imprensa Popular". O projeto considerava inevitável a revolução agrária, a queda do governo Vargas e a sua substituição por um governo democrático de salvação nacional.

Ainda a respeito dessa conjuntura, um rádio telegrama do delegado local comunicou, em 18 de agosto de 1954, que não havia sido realizado o comício da Liga de Emancipação Nacional, acentuando: "esta autoridade esteve vigilante e tomou todas as providências a fim de evitar a realização de tal comício". ${ }^{15}$ Criada em abril de 1954, a liga defendia a nacionalização das

\footnotetext{
${ }^{13}$ Chefatura de Polícia do Estado do Paraná. Radiograma de Maringá no . 5, pl68, dt. 7, em 7 de outubro de 1953. Pasta "Delegacia de Polícia de Maringá". A respeito da "Imprensa Popular", esclareceu Sonia Serra: “A III Conferência Nacional do PCB, realizada em julho de 1946, determinou então como uma tarefa urgente a elevação do nível político e ideológico de todo o partido e considerou a imprensa como o principal elemento para fazer a propaganda de sua política e atividades. Neste sentido, Prestes lançou a Campanha da Imprensa Popular, uma campanha de finanças visando constituir uma rede de jornais legais em todas as localidades onde houvesse condições para tal e dotá-los de oficinas próprias, além de mobilizar todo o partido para melhorar o nível político e técnico dos seus jornais. SERRA, Sonia. Jornalismo político dos comunistas no Brasil: diretrizes e experiências da Imprensa Popular. http://www.compolitica.org/home/ wp-content/uploads/2011/01/gt_jmp-sonia.pdf. Acesso em 15 de maio de 2016.

${ }^{14}$ Pasta “Delegacia de Polícia de Maringá”. Ofício 267-54. 2 de junho de 1954.

${ }^{15}$ Chefatura de Polícia do Estado do Paraná. Radiograma de Maringá nº. 58, pl 31, dt.18, em 18 de agosto de 1954. Pasta "Delegacia de Polícia de Maringá".
} 
fontes de energia elétrica e da distribuição de petróleo, a reformulação da política econômica e uma reforma agrária para o desenvolvimento do país. Era composta por nacionalistas de esquerda, sobressaindo os comunistas.

Nas pastas, não há vestígios a respeito da resposta da DOPS nem dos encaminhamentos. Investigações futuras poderão cercar melhor as evidências factuais contidas nesses registros, incluindo sua própria autenticidade,${ }^{16}$ mas é ilustrativo indicar a contextualização da política nacional do PCB naqueles anos.

Referindo-se ao período entre 1945 e 1964, Kieller e Codato sistematizaram que o PCB esteve envolvido em três grandes movimentos no Paraná: "a campanha pela Paz, a luta pela Imprensa Popular e os conflitos de terras no Norte do estado, em 1948 e 1952, e no Sudoeste, em 1957, dois grandes levantes camponeses". ${ }^{17}$ Nos primeiros anos da década, havia a orientação do "Manifesto de Agosto de 1950", que instituiu a "Frente Democrática de Libertação nacional", e havia a política antivarguista, vigente até o suicídio do presidente. Depois disso, houve uma mudança de atitude diante do trabalhismo. ${ }^{18}$

Para além da intervenção em atividades de forte impacto na conjuntura, como os levantes citados, o PCB dedicou-se ao processo de organização sindical, de forma contínua e persistente, ao longo de todo o período. No Norte do Paraná, havia, entre outras, a demanda dos trabalhadores rurais que atuavam no complexo cafeeiro. Em cidades novas, como era o caso de Maringá, os dirigentes do PCB também contribuíram para a formação das primeiras entidades urbanas.

No município, a exemplo do que já ocorrera em Londrina no final da década anterior, ${ }^{19}$ os comunistas estimularam e lideraram, primeiramente, a formação da União Geral dos Trabalhadores de Maringá (UGTM), fundada em 1956. Tratava-se de uma entidade associativa de perfil genérico, que abrigava assalariados de várias categorias e até mesmo pequenos empresários e

\footnotetext{
${ }^{16}$ Deve-se indagar qual era o sentido de tamanha exposição em um período em que era reformada a legislação de segurança nacional. A Lei 1802, de janeiro de 1953, estabelecia, em seu nono artigo, punição a quem tentasse reorganizar, de fato ou de direito, partido dissolvido por força de dispositivo legal.

${ }^{17}$ KIELLER \& CODATO, Op. cit., p. 55

${ }^{18}$ CARONE, Edgar. O PCB (1943-1964). Vol. 2 . São Paulo: Difel, 1982.

${ }^{19}$ De acordo com Veronika IPÓLITO (Op. Cit, p. 81), a primeira associação do gênero foi a União dos Trabalhadores de Londrina (UTL), fundada em julho de 1948. Em meados da década de 1950 e no início da seguinte, esses organismos seriam criados em outras cidades paranaenses: Maringá, Campo Mourão, Nova Esperança, Loanda, Paranavaí, Goioerê, Querência do Norte e Cascavel.
} 
pequenos proprietários rurais. A UGTM foi uma espécie de célula mãe para a ulterior formação dos sindicatos por categoria.

A UGTM foi tema de um documento que o delegado local remeteu à DOPS, em 11 de julho de 1957, em resposta a um pedido de esclarecimentos, enviado pelo órgão especializado, sobre as atividades da entidade..$^{20}$ Os fatos foram precipitados pela atuação do editorialista Ivens Lagoano Pacheco, dono do principal periódico de imprensa da cidade, intitulado o Jornal. Desde o ano anterior, Pacheco utilizava seu espaço editorial para denunciar a suposta infiltração de comunistas na disputa eleitoral, tendo como provável referência a candidatura de Bonifácio Martins à Câmara de Vereadores. Terminado o pleito, insurgiu-se com a aprovação de um projeto de lei, assinado pela bancada do PR, para que o município destinasse subvenção financeira à UGTM. Os dirigentes da entidade de representação trabalhista foram para o embate e fizeram pesadas acusações contra o empresário, produzindo panfletos de denúncia com o papel timbrado da UGTM. ${ }^{21}$

O delegado local afirmou que não procedia a alegação, que teria sido dita por Ivens Lagoano Pacheco quando estivera na chefatura da polícia de Curitiba, segundo a qual a autoridade policial de Maringá desconhecia as atividades da associação. No ano anterior, na gestão de seu antecessor, agentes da polícia especializada estadual estiveram na cidade e coligiram copioso material da associação. ${ }^{22}$

Além disso, garantiu que a delegacia de Maringá monitorara uma reunião de preparação das atividades de $1^{\circ}$. de maio, mapeando os presentes, os oradores, os discursos e os materiais gráficos produzidos. Durante a sua gestão não teria ocorrido qualquer manifestação pública referente a atos subversivos, a não ser a reunião de $1^{\circ}$. de maio. Ficou à disposição para novas diligências, mas solicitou o envio de agentes especializados de fora, uma vez que os policiais locais seriam facilmente identificados pelos militantes políticos de Maringá.

Em 30 de julho de 1957, encaminhou cópias de materiais produzidos pela UGTM e, como resultado de diligências realizadas, elencou uma série de nomes de "elementos vistos constantemente com os chefes subversivos desta

\footnotetext{
${ }^{20} 21^{\mathrm{a}}$. Delegacia Regional de Maringá. Relatório ao Delegado de Ordem Política e Social. 11 de maio de 1957. Pasta "Delegacia de Polícia de Maringá".

${ }^{21}$ Cf. Panfletos da UGTM disponíveis na pasta "Delegacia de Polícia de Maringá”.

${ }^{22} 21^{\mathrm{a}}$. Delegacia Regional de Maringá. Relatório ao Delegado de Ordem Política e Social. 11 de maio de 1957. Pasta "Delegacia de Polícia de Maringá".
} 
cidade". ${ }^{23} \mathrm{Em} 9$ de novembro de 1956, por meio do serviço rádio telegráfico, o delegado de Maringá já havia solicitado, em regime de urgência, informações sobre os antecedentes políticos de Bonifácio Martins. Não há documentação da resposta.

O monitoramento, nos anos seguintes, privilegiou o adensamento das atividades sindicais, nas quais se destacaram o vereador Bonifácio Martins, cujo mandato parlamentar amparava as demandas das lutas e organizações populares, e os sindicalistas José Rodrigues dos Santos e José Lopes dos Santos. o primeiro foi fundador do Sindicato dos Trabalhadores Rurais, da federação do setor e foi membro da primeira diretoria da Confederação Nacional dos Trabalhadores na Agricultura (Contag). O segundo foi fundador do Sindicato da Construção Civil e da federação da categoria, da qual se tornou presidente. Os três viriam a ser processados após 1964.

O crescimento da rede de sindicatos de trabalhadores rurais no eixo do complexo cafeeiro, cujos polos municipais eram Londrina e Maringá, motivou os bispos das dioceses da região a criarem uma organização concorrente, a Frente Agrária Paranaense (FAP). Essa disputa, intensa ao longo dos primeiros anos da década de 1960, foi inaugurada com um acontecimento dramático. O lançamento da FAP, realizado em uma missa campal em Maringá, foi programado para acontecer simultaneamente ao II Congresso dos Trabalhadores Rurais, evento coordenado pelos sindicalistas ligados ao PCB.

No período imediatamente anterior, o relatório da DOPS registrava que o II congresso dos trabalhadores rurais ocorreria de 12 a 15 de agosto de 1961 em Maringá: "Políticos, muitos dos quais de tendência esquerdista, aderiram ao congresso. $O$ clero, por outro lado, combate, e programou para o dia 15 uma reunião de trabalhadores católicos de três dioceses vizinhas para comemorar o dia da padroeira local (...)". ${ }^{24}$ Em outro informe, lê-se:

II congresso dos trabalhadores rurais (ligas camponesas), conforme informação anterior, reunir-se-á de 12 a 15 de agosto em Maringá. Para o dia do encerramento (...) realizar-se-á uma reunião interdiocesana de trabalhadores católicos, e não será de se admirar que ocorra algum conflito. A comissão do congresso conta com o dep. Francisco Julião, e o secretario Manoel Silva vai a Cuba convidar, pessoalmente, Fidel Castro. Durante o Congresso, possivelmente, criar-se-ão as ligas camponesas no Paraná. ${ }^{25}$

\footnotetext{
${ }^{23} 21^{\text {a }}$. Delegacia Regional de Maringá. Ofício 379/57-reservado, 30 de julho de 1957. Pasta "Delegacia de Polícia de Maringá".

${ }^{24}$ Relatório do Informante do Paraná. Período de 1 a 15 de julho de 1961 , p. 2. Pasta "DOPS relatórios 1960, 1961, 1962, 1963, 1965 e 1966".

${ }^{25}$ Idem
} 
Notam-se as tintas da Guerra Fria (o suposto convite pessoal a Fidel Castro) e certa confusão com outra forma de organização emblemática do período, as ligas camponesas, fato provavelmente motivado pela presença de Francisco Julião. Sintomaticamente, previu-se que os eventos simultâneos poderiam resultar em conflito. No relatório do fato consumado, há as seguintes anotações:

Conforme estava programado, reuniu-se de 12 a 15 de agosto em Maringá, com a presença do Dep. Francisco Julião, criador das Ligas Camponesas, e com a participação de 11 entidades sindicais, inclusive federações; com representação da UPE, pelo seu presidente Ronald Osti Pereira. Elementos de projeção do PTB compareceram, entre eles o Senador Nelson Maculan, Renato Celidônio, grande cafeicultor, deputados Waldemar Daros, Amauri Silva e Leo de Almeida Neves, este candidato a prefeito de Curitiba. Representou o presidente da república o deputado Nestor Duarte. Audiência Pequena. (...) Na mesma data e local, os bispos das 3 dioceses promoveram uma reunião de trabalhadores anticomunistas para a fundação da Frente Agrária Paranaense, com apoio do governo do estado. Reuniu mais de 10.000 pessoas e participação de secretário de Estado. O dep. Nestor Duarte tentou ler a mensagem do presidente da República no que foi impedido pelo bispo de Maringá, por ter estado no congresso do Dep. Julião. Aliás, os políticos que pretenderam tomar parte em ambos os conclaves foram acerbamente criticados pelo bispo que insistia em que "quem não estiver conosco está contra nós". A receptividade das ideias de Julião no Norte do Paraná é pequena. ${ }^{26}$

O relatório não capta a dramaticidade do conflito, que foi mais intenso, estimulado pelo clero. Uma passeata de estudantes católicos marchou contra o congresso sindical, gerando uma espécie de batalha campal. Há bastante produção acadêmica a respeito, baseada em noticiário da imprensa comercial, sindical e partidária, além de testemunhos dos envolvidos. ${ }^{27}$ Os eventos ocorreram dentro da legalidade do período, malgrado a tensão política. Mesmo assim, comprova-se que a DOPS não estava alheia aos fatos e ao embate. Na sequência, os líderes sindicais enviaram ofício ao presidente da República e ao Papa João XXIII, protestando contra a atitude hostil dos católicos. ${ }^{28}$

\footnotetext{
${ }^{26}$ Relatório do Informante do Paraná. Período de 1 a 15 de agosto de 1961, p. 3. Pasta "DOPS relatórios 1960, 1961, 1962, 1963, 1965 e 1966".

${ }^{27}$ PRIORI, A. Lutas sociais e conflitos políticos: alguns temas da história de Maringá (o II Congresso dos Trabalhadores rurais e a formação da Frente Agrária Paranaense.). In DIAS, Reginaldo B; GONÇALVES, J.H.R.(orgs.).Maringá e o Norte do Paraná: estudos de história regional. Maringá: Eduem, 1999; TONELLA, Celene; VILLALOBOS, J.U.G; DIAS, R.B. (orgs). As memórias do sindicalista José Rodrigues dos Santos. Maringá: Eduem, 1999; SILVA, Osvaldo Heller. A foice e a cruz: comunistas e católicos na história do sindicalismo dos trabalhadores rurais do Paraná. Curitiba: Rosa de Bassi, 2006.
}

${ }^{28}$ Documentos contidos na pasta "Sindicato dos Trabalhadores Rurais de Maringá". 
No material reunido nas pastas intituladas "Delegacia de Polícia de Maringá", ainda podem ser encontrados recortes de noticiários envolvendo o embate político no campo sindical. Em 1962, por exemplo, o sindicato dos trabalhadores rurais protestava contra notícia segundo a qual a entidade não teria reconhecimento oficial do Ministério do Trabalho. Esse foi um tema delicado no período, em razão da disputa de território entre os sindicalistas ligados ao PCB e os líderes católicos. Os bispos alegavam que tinham mais dificuldade de obter o reconhecimento oficial das entidades que articulavam, dada a coloração política do governo Goulart. A respeito do polo católico, o noticiário registrava reunião de pequenos ruralistas em defesa da família do trabalhador no campo, ocorrida em janeiro de 1963. Os líderes do sindicalismo qualificado como "vermelho" viriam a ser processados em 1964.

\section{A vigilância no período da ditadura}

Em 1964, os movimentos sindicais e os líderes de esquerda de Maringá foram atingidos pela chamada "Operação limpeza" patrocinada pela nascente ditadura, impulsionada pelo Ato Institucional no.1.

Em 10 de abril de 1964, o delegado de polícia de Maringá encaminhou o seguinte rádio telegrama para a DOPS: "Tenho satisfação comunicar vossência uma multidão incalculável comemoravam tarde ontem vitória forças democráticas vg realizando marcha com presença todas autoridades locais et região decorrendo absoluta ordem sds". ${ }^{29}$ Deduz-se que o delegado fez referência a uma "Marcha da Família com Deus Pela Liberdade", noticiada pelo periódico Folha do Norte do Paraná em 5 de abril de 1964, embora se constate desencontro na data.

Em 11 de abril de 1964, poucos dias após a deposição do presidente Goulart, o delegado de polícia de Maringá, por meio de ofício, denunciou três cidadãos do município à DOPS: Gregório Sepúlveda, José Lopes dos Santos e Jorge Ferreira Duque Estrada. Originário da tradição trabalhista, este último era advogado, fora vereador pelo Partido Trabalhista Brasileiro (1952-56) e havia sido candidato a prefeito, em 1960, pelo Partido Social Trabalhista, na chapa por meio da qual Bonifácio Martins foi reeleito. Foi acusado de subversivo por "sempre" ter sido apoiado pelos comunistas. O segundo era sindicalista, presidente do sindicato da construção civil e da federação da

${ }^{29}$ Pasta "Delegacia de Polícia de Maringá". 
corporação. O primeiro foi tachado como "notório comunista", morador do município desde $1947 .^{30}$

Naqueles dias, houve algumas detenções envolvendo pessoas com residência ou procedência de Maringá: Jorge Ferreira Duque Estrada, advogado, de 12 a 20 de abril de 1964; Gregório Cipriano Sepúlveda, comerciante, de 12 de abril a 18 de maio de 1964 e de 28 de maio a 13 de junho de 1964; José Lopes dos Santos, carpinteiro e sindicalista, de 12 a 19 de abril de 1964; Guaracy Nobre Rolim, funcionário sindical, de 12 a 24 de abril de 1964; Emanuel José de Moura, advogado, de 9 a 27 de junho de 1964; Salazar Barreiros, advogado, de 9 a 29 de junho de $1964 .^{31}$

Sobre os três últimos, essa pasta não oferece informações detalhadas, mas sabe-se que eram ligados ao mundo sindical na região de Maringá. ${ }^{32}$ Gregório Sepúlveda e José Lopes dos Santos viriam a ser indiciados, juntamente com Bonifácio Martins, no Inquérito Policial Militar (IPM) que atingiu a cidade, do qual também constariam os nomes do advogado Jorge Haddad e do sindicalista José Rodrigues dos Santos..$^{33} \mathrm{~A}$ Câmara de Vereadores de Maringá chegou a abrir procedimento para estudar a cassação do mandato de Bonifácio Martins, que havia sido reeleito em 1960. Por motivos de segurança pessoal e familiar, o vereador evadiu-se da cidade e abandonou o mandato, mas a Câmara não promoveu sua cassação. Após análise prévia, concluiu que não havia base legal para a decisão e resolveu enviar o material produzido para apreciação das autoridades federais. ${ }^{34}$

As maiores represálias recaíram sobre os cinco indiciados no IPM. Bonifácio Martins, José Rodrigues dos Santos e José Lopes dos Santos foram condenados à revelia em 1970. Os dois primeiros cumpriram pena. O terceiro não foi localizado para cumprir a pena que lhe foi imputada. Jorge Haddad e Gregório Sepúlveda foram absolvidos. Esse processo está disponível nos arquivos do projeto "Brasil: nunca mais", catalogado como BNM 69.

Não obstante o desmantelamento dos movimentos existentes antes do golpe de 1964, houve rearticulação de lutas sindicais e estudantis nos últimos

\footnotetext{
${ }^{30}$ Pasta "Delegacia de Polícia de Maringá".

${ }^{31}$ Pasta "Revolução - MAR - 64".

${ }^{32}$ Por meio do ofício 139/64, de 14 de abril de 1964, o delegado de Maringá notificou o nome de Emanuel Moura, informando que era vereador em Mandaguaçu. Essa também era a condição de Salazar Barreiros. Ambos eram advogados do meio sindical. Pasta "Delegacia de Polícia de Maringá".

${ }^{33}$ ARQUIDIOCESE DE SÃO PAULO. Perfil dos Atingidos. Petrópolis: Vozes, 1988, p. 251.

${ }^{34}$ DIAS, R. B. Maringá no nascimento da ditadura civil-militar de 1964: análise do processo movido contra o vereador Bonifácio Martins e seus desdobramentos. In Antíteses. Londrina. Vol. 8 nov. 2015.
} 
anos daquela década, em ligação com as novas organizações de esquerda do período. No território do município, está documentada a atuação da Ação Popular (AP) e do Partido Comunista Brasileiro Revolucionário (PCBR). A primeira buscou ramificação a partir do deslocamento de um de seus principais dirigentes estaduais, o advogado Edésio Passos, e integrou-se à reorganização do movimento sindical. O PCBR formou-se, fundamentalmente, a partir da radicalização de núcleos de estudantes.

\section{O ano de 1968 em Maringá}

De maio a outubro de 1968, Maringá viveu uma conjuntura de ascensão do movimento sindical. Os diferentes episódios foram devidamente acompanhados pelos órgãos de vigilância, que legaram farta documentação de suas incursões.

A rearticulação do sindicalismo vinha ocorrendo, no mínimo, desde o ano anterior, mas a mobilização de 1968 começou a ter visibilidade nos atos de $1^{\circ}$. de maio. Como se lê em seu relatório, a 13a. Subdivisão Policial montou um esquema de segurança, com agentes trajados como civis. Os discursos foram gravados e encaminhados à Secretaria de Segurança. A delegacia considerou que não houve nada de anormal, mas abriu investigações sobre os líderes do movimento, o advogado Edésio Passos e José Lopes dos Santos. ${ }^{35}$ Nesse dia, foi publicada uma pauta de reivindicações dos sindicatos em "O Jornal" e uma entrevista com José Lopes dos Santos.

Em 27 de agosto, foi elaborado outro relatório mais abrangente, dando conta da evolução dos fatos sindicais que envolviam algumas categorias profissionais. Inicia reportando-se às comemorações de $1^{\circ}$. de maio. Depois disso, registra a ocorrência da $1^{\mathrm{a}}$ Convenção dos Bancários do Paraná, sediada em Maringá no período de 13 a 15 de junho. ${ }^{36}$

Na tentativa de identificar os líderes, faz referência ao advogado Edésio Passos e aos sindicalistas Jair Ferreira e José Lopes dos Santos. Ferreira era presidente do sindicato dos bancários e Santos tornara-se presidente da Associação Profissional dos Trabalhadores nas Indústrias Alimentícias. O relatório narra a mobilização dos operários da Cia. Norpa Industrial, do setor alimentício, sob a liderança do citado advogado e de José Lopes dos Santos. A

\footnotetext{
${ }^{35}$ Relatório da 13a. SDP. Relatório, 5 de maio de 1968. Pasta "Associação Profissional dos Trabalhadores nas Indústrias Alimentícias".

${ }^{36}$ Relatório "Sobre o movimento sindical ocorrido na cidade de Maringá e circunvizinhanças, durante os meses de maio a agosto de 1968", 27 de agosto de 1968. Pasta "DOPS relatórios (1967 e 1968)".
} 
pauta sistematizava questões trabalhistas. Já havia a hipótese de paralisação, fato que seria consumado em outubro.

Sem a necessidade de cotejar minuciosamente sua narrativa com os fatos ocorridos, nota-se que o agente policial demonstra conhecimento da evolução da campanha reivindicatória: reuniões, pauta etc. Teria havido "início de subversão", mas a situação estava mais calma. O relatório aponta eventual infiltração no periódico "O Jornal”, em razão do noticiário dos atos de 1º. de maio e da entrevista com o líder sindical. Identifica que Edésio Passos havia sido dirigente do extinto PSB e respondera a IPM em 1964. Não demonstra conhecimento, porém, de suas vinculações mais recentes: era dirigente estadual da organização revolucionária Ação Popular, em nome da qual viera atuar politicamente em Maringá.

Em conclusão, "a situação atual da cidade de Maringá é bastante agitada na parte sindical, pois líderes comunistas fazem um campo de batalha com referência aos funcionários da fábrica Norpa Industrial". ${ }^{37}$ Adverte:
A situação em Maringá requer um policiamento mais ativo e organizado, para acompanhar os movimentos sindicais. Atualmente, a subdivisão policial daquela localidade encontra-se sem delegado titular e sem recursos, e, para acompanhar os movimentos subversivos, que ora se alternam pelo Norte do Paraná, sendo Maringá uma sede Subdivisional, requer-se um melhor policiamento, a fim de não se perder de vista o movimento que eclode. ${ }^{38}$

De acordo com sua avaliação, os sindicatos estavam em franco movimento e o quadro inspirava cuidados. Alerta que a entidade que coordenava o movimento, a Associação Profissional dos Trabalhadores nas Indústrias Alimentícias, não tinha o estatuto de sindicato e poderia ser fechada pela autoridade policial. A mobilização atingiria seu auge em outubro de 1968, quando foi deflagrada a greve da Cia. Norpa e houve um ensaio de greve geral no âmbito do município.

A I Convenção dos Bancários, realizada de 13 a 15 de junho de 1968, mereceu uma pasta própria. Desde agosto de 1967, relatórios registravam ações das lideranças em favor de campanhas reivindicatórias, com participação em eventos mais amplos da corporação, como se lê em boletim recolhido pelo serviço de vigilância. Eis uma passagem importante, emblemática do peculiar modo de interpretação do agente policial:

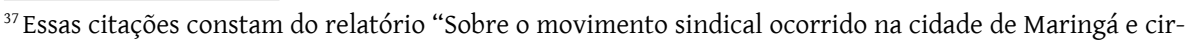
cunvizinhanças, durante os meses de maio a agosto de 1968”. DOPS, 27 de agosto de 1968.

${ }^{38}$ Ibidem, p. 5.
} 
Os oradores, de modo geral, fizeram críticas abertamente ao Presidente da República, no campo da política salarial do governo, citando que o representante da Nação nada mais é do que mero instrumento mancomunado com os Trustes internacionais (salientando os Estados Unidos) e que, além de vendilhão da Pátria, obedece cegamente as ordens recebidas de organizações internacionais. ${ }^{39}$

Foram incorporadas cópias das teses apresentadas pelos sindicalistas e uma ata oficial do evento. Concretamente, o agente constata o repúdio à política salarial, à Lei de greve e a defesa da "anistia às vítimas da falsa revolução". Emite o seguinte parecer:

A meu ver, Maringá está servindo de base para tipos de propagandas de caráter extremista e que sigilosamente alastram-se aqui movimentos escusos aos interesses nacionais, porquanto anteriormente já foi sede de encontro dos trabalhadores rurais do Paraná e gradativamente na mente de seus habitantes vai sendo incutida uma nova mentalidade de oposição e rebeldia , podendo, se não haver (sic) paradeiro, trazer em um futuro bem próximo consequências imprevisíveis, vistos os métodos violentos de atacar o governo e apontar falhas em sua administração, usado pelos sindicatos locais e pessoas já acostumadas a tal prática de doutrinação. As orações são feitas de maneiras ardilosas e comoventes, procurando incutir emocionalmente nos assistentes e filiados ao movimento sindical um novo panorama de vida. ${ }^{40}$

Em outro documento, com o característico exagero, os agentes de segurança afirmam:

Embora os organizadores não divulgassem os motivos de terem escolhido Maringá como sede, parece que de fato estão sentindo que essa cidade é a que apresenta maior movimentação no setor sindical, oferecendo excepcional ambiente, dentro do que já foi divulgado ser Maringá a cidade escolhida pelo IV congresso Internacional do PC como cidade chave para a movimentação esquerdista em sua área geográfica. ${ }^{41}$

Há um conjunto bem robusto de documentos, anexados aos relatórios ou presentes em pastas dedicadas às entidades que estiveram na órbita da mobilização, que demonstram a evolução do quadro sindical desde maio. Na pasta "Sindicato dos Trabalhadores nas Indústrias Metalúrgicas Mecânicas", há uma cópia de um ofício que circulou entre entidades sindicais do setor visando a uma campanha salarial em setembro de 1967. Ainda contém um manifesto dos metalúrgicos apresentado em 1ํ. de maio de 1968. Na pasta "Sindicato

\footnotetext{
${ }^{39} 13^{\text {a }}$. Subdivisão Policial de Maringá. Relatório, 17 de junho de 1968, p. 1. Pasta “Convenção Estadual dos Bancários do Paraná".

${ }^{40}$ Ibidem, p. 4.

${ }^{41}$ Idem
} 
dos Trabalhadores na Indústria da Construção Civil e do Mobiliário”, há um documento, datado de maio de 1968, por meio do qual a entidade adverte as autoridades, incluindo a DOPS, que manteria protesto contra uma prestigiada empresa da cidade, em razão de desmandos administrativos.

A articulação caminhou para a deflagração, no início de outubro, de uma greve geral na cidade. A entidade que exerceu maior protagonismo foi a Associação Profissional dos Trabalhadores nas Indústrias Alimentícias, acompanhada pelo Sindicato dos Bancários. Foram as duas categorias que efetivamente promoveram paralisação em outubro.

No caso dos bancários, em sincronia com o movimento nacional da categoria, mobilizada por causa da data-base, a greve foi parcial e rápida. No caso das indústrias alimentícias, confirmou-se a paralisação da Cia. Norpa Industrial, em cuja base a entidade de classe havia feito efetiva preparação, e houve a adesão não esperada dos operários da Cia. Cruzeiro. Não chegou a ocorrer a paralisação generalizada, mas houve um clima de ampla mobilização, visto que outras entidades manifestaram apoio e foi constituído um comitê de solidariedade.

Os quatro primeiros relatórios revelaram o olhar dos órgãos de vigilância sobre a deflagração e o desenvolvimento inicial do movimento. ${ }^{42} \mathrm{Em}$ resumo, procuraram mensurar os níveis de adesão e o potencial de irradiação. No setor alimentício, por exemplo, era considerada a hipótese de paralisação dos trabalhadores de uma grande empresa, a Sanbra (Sociedade Algodoeira do Nordeste do Brasil). Da mesma forma, é apontada a possibilidade de adesão das empresas de transporte coletivo urbano.

Também é registrada a penetração nos meios estudantis, principalmente entre os secundaristas, adicionando que talvez houvesse uma passeata de apoio. Os agentes asseguraram que a polícia militar acompanhava de perto a situação e monitorava todas as áreas de abrangência do movimento. Foram anexados panfletos produzidos por todas as entidades envolvidas.

A Informação n⿳. 26 PM 2/68, editada em 7 de outubro, apontou tendência de esvaziamento do movimento. 0 agente de vigilância dedica-se mais à identificação de personagens e a uma apreciação ideológica do que à descrição dos fatos. O relatório preocupa-se com as palavras de ordem que estariam sendo veiculadas e teriam conteúdo revolucionário:

${ }^{42}$ Informação nº. 21 PM 2/68, 2 out 1968; Informação nº. 22 PM 2/68, 4 out 1968; Informação nº. 23 PM 2/68, 4 out 1968; Informação no. 24 PM 2/68, 5 out de 1968 - Pasta "Movimentos Grevistas em Maringá." 
Explorando a condição de ser Maringá cidade relativamente afastada dos grandes centros e, portanto, receber com atraso as notícias desses e também por não contar com imprensa ou rádio que transmitam a real situação da conjuntura nacional, difundem e exploram notícias inteiramente falsas, ou então meias verdades, com o intuito, alias, por eles declarados, de conduzir a massa a uma revolução para a derrubada do regime vigente. Afirmam suas lideranças, entre outras notícias inverídicas, por exemplo, que a nação inteira se encontra em greve e que as forças da repressão, em sua ação, tem ocasionado inúmeros mortos, inclusive em Curitiba. As locuções que os nominados (...) transmitem às massas, bem como os panfletos e boletins por eles distribuídos - (cujas cópias oportunamente remeteremos a esse órgão) são extraordinariamente violentos. Conclamam o povo ao emprego da violência e abertamente apregoam uma "revolução", em forma de "guerra popular": para "a derrubada da ditadura" e a formação de um "governo de operários e camponeses". ${ }^{43}$

A documentação não comenta o desfecho da greve, mas houve esvaziamento e represálias aos envolvidos. O dossiê reunido pela DOPS contém um documento que revela tentativa de enquadrar a greve como infração à segurança nacional, com a alegação de que havia interrompido atividades de um setor essencial, o de abastecimento de alimentos. A denúncia não foi acolhida. ${ }^{44}$

Os panfletos sistematizavam as reivindicações conjunturais com palavras de ordem contra a ditadura e de sentido anti-imperialista. O principal articulador da greve, o advogado Edésio Passos, era dirigente da organização revolucionária Ação Popular, defensora da estratégia da revolução camponesa. Não se sabe se esses materiais efetivamente circularam entre os operários, mas o dossiê incorpora um exemplar do jornal "A libertação", editado pela Ação Popular, e outro texto abordando a revolução chinesa e a guerra popular. ${ }^{45}$

Saliente-se que esses relatórios não registravam o vínculo de Edésio Passos com a Ação Popular (AP). Eventualmente, é referido como comunista em alguns documentos e se acusa seu vínculo passado com o PSB. Já no ano anterior, Passos viera para Maringá, acompanhado de sua esposa, também militante da AP, Zélia Passos. O objetivo era coordenar a sedimentação, no médio prazo, de sua estratégia da revolução camponesa, embora sua principal atuação no período, decorrente de sua formação profissional, tenha privilegiado a articulação dos sindicatos urbanos. Com a visibilidade que adquiriu e

\footnotetext{
${ }^{43}$ Informação no. 26 PM2 68, 7 out 1968, p. 2. Pasta “Movimentos Grevistas em Maringá".

${ }^{44}$ A Auditoria da 5 ${ }^{a}$. Região Militar recusou a tese, mas o procurador recorreu ao Superior Tribunal Militar. o documento que formaliza o indeferimento do recurso, datado de 30 de julho de 1969, está disponível na pasta “Associação Profissional dos Trabalhadores nas Indústrias Alimentícias”.

${ }^{45}$ Pasta "Movimentos Grevistas em Maringá".
} 
com o recrudescimento da repressão após a edição do AI-5, foi transferido para outro estado, onde foi detido. ${ }^{46}$ Respondeu a processo pelo seu envolvimento na AP. Com essa dinâmica, houve renovação da direção da AP no Paraná e reorganização do núcleo de Maringá em 1970. As ações, contudo, voltaram-se para o trabalho no meio rural, principalmente na região de Goioerê, onde teve participação em um movimento de arrendatários. ${ }^{47}$

José Lopes dos Santos, sempre citado nos documentos, havia sido processado em 1964. Mantinha vida legal e visibilidade em Maringá naquela conjuntura, mas o processo iniciado em 1964 ganharia novas fases no final da década, vindo a ser julgado e condenado à revelia em 1970. Não consta que tenha sido detido e cumprido pena até a anistia de 1979. Logo após a greve de outubro, evadiu-se de Maringá.

Os relatórios citam o apoio de líderes estudantis à greve de outubro de 1968, sem fornecer detalhamento, e aventam a possibilidade de uma manifestação de apoio ao movimento paredista. Logo em seguida, perseguindo objetivos próprios, houve uma grande manifestação estudantil em Maringá, comandada por lideranças do ensino secundarista, quando da presença do governador Paulo Pimentel. ${ }^{48}$

Em pastas especificamente dirigidas a essa finalidade podem ser colhidos subsídios para a compreensão da dinâmica do movimento estudantil local. Na época, o ensino superior encontrava-se em fase de implantação em Maringá, com a existência de três faculdades. A universidade só seria criada em 1969 e implantada a partir de 1970. Formava-se uma geração de líderes estudantis, sobretudo nos meios secundaristas, que se articulou com o movimento estadual de resistência contra a ditadura e acabou relacionando-se com organizações da esquerda revolucionária.

Uma expressão era o Movimento Estudantil Livre (MEL), definido da seguinte maneira por um documento dos órgãos de repressão:

O movimento estudantil livre tem uma posição política que é basicamente definida na luta contra a política educacional do governo. Ele se propõe a conduzir as lutas secundaristas, face à subordinação das pretensas lideranças ao

\footnotetext{
${ }^{46} \mathrm{Cf}$. Pasta individual de Edésio Passos.

${ }^{47}$ Foram estabelecidos dois Comandos Seccionais para reorganizar as atividades da AP no Paraná. O primeiro abrangia a região de Curitiba, enquanto o segundo abarcava o Norte e o Noroeste do estado, subdividindo-se nas seguintes áreas: Ouro (Maringá), Prata (Londrina). Relatório 003/72 - DOPS-PR. Pasta "Ação Popular Marxista-Leninista do Brasil".

${ }^{48}$ Os fatos foram relatados por um dos protagonistas em crônica publicada na década de 1980. MAIOR, Laércio Souto. Tempo quente. In Revista Pois é. Maringá, no. 6, jan. 1987.
} 
esquema governamental (entidades pelegas). As lutas do movimento estudantil tendem, necessariamente, a se tornarem lutas políticas. ${ }^{49}$

Em seu diagnóstico, o relatório afirma:

Um dos bastiões do movimento estudantil livre está localizado em Maringá integrando os seguintes elementos: Ramirez Moacir Pozza (Coordenador regional do MEL), Francisco Timbó de Souza e Natan Pereira Barbosa, este último preso naquela cidade, em noite de 11 do corrente, quando, juntamente com outros estudantes, promovia "comício relâmpago" dentro de uma concentração política realizada na Praça Raposo Tavares, à qual se fazia presente o governador Paulo Pimentel. ${ }^{50}$

\section{PCBR e Operação Marumbi}

Conforme memória de seus militantes, o PCBR foi constituído em Maringá a partir da confluência de duas vertentes de estudantes. Uma vinha do Colégio Estadual Dr. Gastão Vidigal e foi iniciada nos debates políticos pelo trabalho de promoção humana coordenado por uma freira, inspirado na obra do Padre Lebret. ${ }^{51}$ A outra vertente era de militantes que, inicialmente, haviam constituído um agrupamento local, denominado apenas como "a organização", usando a fachada de um Centro Cultural. ${ }^{52}$

Na pasta que a DOPS dedicou ao PCBR, há um relatório que discrimina a dinâmica de sua constituição no Paraná. Como o documento foi elaborado a partir de depoimentos colhidos com métodos repressivos, a utilização dos dados demanda cuidado, mas é possível filtrar, com certa verossimilhança, uma narrativa:

(...) Conclui-se que o PCBR foi estruturado na região Norte do Paraná da seguinte forma: Comitê Zonal 1- Londrina (...); Comitê zonal 2, sediado em Maringá e abrangendo municípios vizinhos. Teve sua estruturação iniciada em reunião em sítio (...), com representantes do CZ 1. Saul (Elinor Mendes de Brito), como representante do partido (...), aproximadamente em maio ou junho de $1969 .{ }^{53}$

Elinor Mendes de Brito, líder estudantil oriundo da Guanabara, havia sido designado para coordenar a área do Norte do Paraná e dar assistência aos

\footnotetext{
${ }^{49}$ Informação 32/68-16.10, fl 3. Pasta "Movimento estudantil Livre".

${ }^{50}$ Ibidem, fl 1 .

${ }^{51} \mathrm{Cf}$. depoimentos de Licínio Lima, ex-dirigente do PCBR em Maringá.

${ }^{52} \mathrm{Cf}$. depoimento de Laércio do Souto Maior, ex-dirigente do PCBR em Maringá.

${ }^{53}$ Relatório ao IPM instaurado pela Portaria no 13 AP, de 28 de agosto de 1970, p. 3. Pasta "Partido Comunista Brasileiro Revolucionário".
} 
militantes da região. Informa-se que membros de Maringá compunham, até então, um grupo independente e concordaram com as condições propostas. Havia a necessidade de aceitar as teses dos documentos "O caminho armado" e a "Realidade brasileira". Também foram formadas ou esboçadas organizações de base no meio estudantil, no meio operário rural e no meio operário urbano.

Segundo esse relatório, foram indiciados 13 militantes com domicílio em Maringá..$^{54}$ Trata-se da Ação Penal 616/1972, catalogada pelo projeto "Brasil: nunca mais" como BNM 282. 0 objeto da acusação foi assim resumido: agrupamento perigoso à segurança nacional; posse ilícita de armamentos. Haveria suposta infração aos artigos 43 e 46 do Decreto Lei 898/1969, que definia os crimes contra a Segurança Nacional. Todos foram absolvidos pelo Conselho de Sentença em 18 de junho de 1973. Até pelos nomes discriminados, a composição era basicamente de estudantes secundaristas e universitários. Foram promovidos grupos de estudos para adesão de novos membros. ${ }^{55}$ Considerando que o ingresso da maioria teria ocorrido em meados de 1969 e que o inquérito foi aberto um ano depois, há uma baliza para avaliar a duração e os limites das atividades do PCBR em Maringá.

Em janeiro de 1970, a delegacia de polícia registrou a ocorrência de um "derrame de panfletos subversivos" nas localidades de Floresta e Floriano, respectivamente, um município próximo e um distrito de Maringá. Os panfletos tinham o título de "Ação Camponesa". Os documentos não são conclusivos sobre a responsabilidade, mas as hipóteses mais sustentadas levavam aos estudantes que haviam feito parte do MEL, alguns dos quais se envolveram com o PCBR, com apoio de um vereador. ${ }^{56}$

Depois desses episódios, a principal intervenção dos órgãos repressivos envolvendo militantes de esquerda de Maringá ocorreu em 1975, no curso da “Operação Marumbi”.

A literatura especializada informa que o aparato repressivo, após a vitória do Movimento Democrático Brasileiro (MDB) nas eleições de 1974, desencadeou ofensiva contra o PCB, partido que ironicamente havia optado pela resistência pacífica e não havia se envolvido em ações armadas contra

\footnotetext{
${ }^{54}$ É pertinente a observação de uma pesquisa acadêmica sobre as prisões no Paraná: "Possivelmente nem todos esses nomes tinham vinculação orgânica com o PCBR. Muitas vezes pequenas ligações já eram o suficiente para comprometer politicamente perante a repressão". DELLA VECCHIA, R.S. Origens e evolução do Partido Comunista Brasileiro Revolucionário (1967-73). Dissertação de mestrado em Ciência Política. Porto Alegre: Universidade Federal do Rio Grande do Sul, 2005, p. 144.

${ }^{55}$ Relatório ao IPM instaurado pela Portaria no. 13 AP, de 28 de agosto de 1970. Pasta "Partido Comunista Brasileiro Revolucionário".

${ }^{56}$ Pasta "Delegacia de Polícia de Maringá".
} 
o regime. Na lógica da suspeição, ainda que por outros meios, o PCB estaria conspirando e lhe foi atribuída responsabilidade na vitória do $\mathrm{MDB} \cdot{ }^{57} \mathrm{No}$ Paraná, a operação ficou conhecida como "Marumbi".

Formalmente, trata-se do IPM 745, que acusou militantes de tentarem rearticular o partido clandestino, supostamente infringindo o Decreto Lei 898/1969. A operação atingiu 12 cidades e envolveu dezenas de indiciados, cinco dos quais domiciliados em Maringá. Como era comum, houve denúncia de prática de torturas nas fases preliminares. Em outubro de 1977, os cinco maringaenses foram absolvidos pelo conselho de sentença. ${ }^{58}$

\section{A Universidade Estadual de Maringá}

No âmbito da Universidade Estadual de Maringá (UEM), houve fatos que motivaram a vigilância dos serviços de segurança. Criada em 1969 e implantada em 1970, a UEM viveu um período de transição até seu reconhecimento oficial em 1976, quando um processo administrativo interno estabeleceu a definitiva adaptação de estruturas aos preceitos da Lei Federal 5540/68. Além dos mecanismos já existentes, em conformidade com a legislação federal, a universidade constituiu sua Assessoria de Segurança e Informações (ASI), integrada ao Sistema Nacional de Informações, em 6 de abril de 1977 (Resolução 20/77 - CAD). É fato bem documentado que a assessoria já existia nos anos anteriores à regulamentação.

Assinale-se que, no seio das faculdades que precederam a universidade e que deram suporte à sua formação, houve, no final da década de 1960, alguns fatos dignos de nota. Em 1969, houve o indiciamento do acadêmico Philemon de Assis Vieira, presidente do Diretório Acadêmico Nelson Hungria, da Faculdade de Direito, no Decreto Lei 477, sob a acusação de ter utilizado as dependências da instituição para provocar subversão. O motivo era desproporcional à acusação. Na organização da Semana da Pátria, o presidente afixou um edital protestando contra a impossibilidade de "fazer um debate franco e aberto", texto que as autoridades, influenciadas pela ideologia da segurança nacional, consideraram subversivo..$^{59}$ De qualquer forma, alguns estudantes universitários, notadamente das faculdades de Economia e de Filosofia, Ciências e Letras, engajaram-se em uma organização revolucionária, o PCBR.

\footnotetext{
${ }^{57}$ BRUNELO, Leandro. Repressão durante o regime militar no Paraná: o caso da operação Marumbi na terra das araucárias. Maringá: Eduem, 2009.

${ }^{58}$ Pasta “PCB” (PT 1491.179).

${ }^{59}$ Pasta Individual "Philemon de Assis Vieira".
} 
A incipiente universidade, já em 1972, gerou um fato que mereceu um relatório (9/72) da polícia civil. Esse documento registrou a hipótese de eclosão de protesto estudantil na UEM por causa de uma portaria, baixada pela reitoria, que impedia a frequência de alunos inadimplentes. Havia rumores de que poderia haver uma greve e de que o reitor utilizaria o Decreto Lei 477. No final, o agente policial apontou que o impasse tendia a ser superado mediante parcelamento das dívidas. ${ }^{60}$

Produzidos pela assessoria interna de informação e por outros órgãos de vigilância, há materiais diagnosticando a imprensa estudantil que circulava na UEM, as pautas e os responsáveis pelos jornais. Exemplo é o conteúdo do documento 324/DI/75-CISESP-PR. ${ }^{61} \mathrm{No}$ mapa que elaborou, dissecou o jornal 0 Brado universitário e seu vínculo com o DA Nelson Hungria. Salientou a participação do acadêmico Laércio Souto Maior, "processado por ações subversivas na região". ${ }^{62}$ Acusou, ainda, a existência de duas outras manifestações da imprensa dos estudantes. A primeira era o Suplemento universitário, publicado em O Jornal. O responsável pelo suplemento, Francisco Timbó de Souza, acadêmico de Direito e vereador pelo MDB, foi citado como agitador já fichado na DOPS. ${ }^{63}$ A outra publicação era o jornal o grito universitário, editado pelo Diretório do Instituto de Ciências Exatas e Tecnologia. Para não se sujeitarem às normas internas, os jornais circulavam como encarte de O Diário do Norte do Paraná.

Nesse conjunto de registros, também podem ser encontrados materiais de qualificação das eleições à diretoria do DA Nelson Hungria. Reproduz-se o programa da Chapa União, inscrita ao pleito de 1975, do qual constavam compromissos com a defesa do ensino gratuito e com a democratização da universidade e do país. Há especulações sobre o vínculo do candidato a presidente, Ricardo Antônio Balestra, com as alas radicais do MDB, partido ao qual era filiado. ${ }^{64}$

Nos dois primeiros anuários estatísticos produzidos a partir do reconhecimento oficial da UEM, relativos aos anos de 1976 e 1977, havia um espaço para a quantificação dos trabalhos da ASI, como se pertencessem à rotina administrativa. De 1978 em diante, contudo, a assessoria deixou de compor o caderno estatístico. Até onde foi possível investigar, os arquivos da

\footnotetext{
${ }^{60}$ Delegacia de Ordem Política e Social. Relatório, 27 de novembro 1972. Pasta “DOPS 3 (70 71 72)".

${ }^{61}$ Pasta "Fundação Universidade Estadual de Maringá".

${ }^{62}$ Detido e processado por vinculações ao PCBR em 1970 e detido e processado na Operação Marumbi.

${ }^{63}$ Era visado desde os tempos de estudantes, tendo sido identificado como membro do Movimento Estudantil Livre. Apesar das tintas fortes dos apontamentos da DOPS, sempre foi militante do MDB.

${ }^{64}$ Pasta "Universidade Estadual de Maringá".
} 
universidade não preservaram esse conjunto documental. Na DOPS, localizou-se apenas uma pequena amostragem.

No final daquela década, o movimento estudantil voltaria a ser alvo de robustos registros. Em 1979, já na conjuntura de abertura política, ocorreu uma mobilização pelo congelamento das mensalidades. Houve manifestações públicas, elaboração de materiais com exposição de motivos para autoridades e para a população, busca de negociação com o governo do estado. $\mathrm{Na}$ deflagração do processo, aproveitando a agenda do governador Ney Braga em Maringá, líderes estudantis, escudados por uma manifestação, tentaram uma audiência. $O$ episódio foi cercado por muita tensão.

Nos arquivos da DOPS/PR, há denso material a respeito dessa mobilização. O Informe - PM 937/79 relata os principais acontecimentos: as manifestações, as assembleias estudantis, a divulgação de panfletos e uma audiência com o secretário da Educação. Também procura identificar os eventuais responsáveis. Há cópias dos documentos aprovados pela assembleia estudantil que elegeu uma comissão para negociar, composta pelos presidentes dos diretórios e pelos representantes de cursos. A vigilância focalizava líderes estudantis ligados ao MDB e ao PCB. ${ }^{65}$

A recém-fundada Associação dos Docentes da UEM também motivou a atenção da assessoria de informação. Em 7 de maio de 1979, o Informe 242-PM elaborou qualificação da diretoria da entidade. Novos apontamentos datam do início da década seguinte. A greve dos docentes da UEM, ocorrida no final de 1980, motivou a coleção de vários recortes de jornais em uma das pastas dedicadas à instituição. ${ }^{66}$

Em 1981, o Diretório Central dos Estudantes (DCE) da UEM, criado no final do ano anterior, foi fechado por um procedimento administrativo disciplinar, um fato que gerou polêmica e mobilização na conjuntura. Foram preservados vários recortes de jornais a respeito. ${ }^{67}$ O Informe 201/81, produzido pela Assessoria de Informação da Universidade Estadual de Londrina (UEL), sistematizou a identificação política das chapas que concorriam ao DCE da UEM, resumiu o programa de cada uma e anotou o resultado do pleito. ${ }^{68}$

\footnotetext{
${ }^{65}$ Pasta “Universidade Estadual de Maringá”. Ver DIAS, Reginaldo B. Uma universidade de Ponta-cabeça. Maringá: Eduem, 2007.

${ }^{66}$ Pasta “Fundação Universidade Estadual de Maringá”.

${ }^{67}$ Pasta "Universidade Estadual de Maringá".

${ }^{68}$ Pasta "Diretório Central dos Estudantes UEM".
} 


\section{Novas manifestações de sindicalismo}

Elaborado em 23 de agosto de 1979, um relatório da Polícia Militar informou que a oposição bancária, como forma de alavancar seu potencial eleitoral, projetava um amplo evento político com a presença de Luiz Inácio Lula da Silva e outros expoentes do chamado novo sindicalismo, como Luiz Gushiken e Jacob Bittar. Confundindo as siglas, o agente anotou que "Lula pretendia fazer contatos para a criação do Partido Trabalhista Brasileiro". ${ }^{69}$ Na última hora, uma negociação no Congresso Nacional exigiu a presença do líder operário e a agenda - que incluía atividades em Londrina e em Curitiba - restou inviabilizada. 0 dossiê ainda reuniu várias informações sobre a chapa de oposição. Por seu turno, o Informe 754/1979-PM reportou assembleia da Associação dos Professores do Paraná, realizada no Colégio Estadual Dr. Gastão Vidigal. ${ }^{70}$

Em julho de 1981, a 9. Subdivisão Policial de Maringá, por intermédio do ofício 497/81, sistematizou um relatório acerca de um Encontro de Trabalhadores Sindicais, envolvendo algumas entidades de Maringá e da região. $O$ agente sublinha que não houve a proposição de formação de uma central sindical nem a apresentação de reivindicação das classes. Os temas pertinentes foram deixados para um congresso que seria realizado em Curitiba, do qual a reunião de Maringá era uma etapa preparatória. Pelo que se pode inferir, tratava-se de uma preparação para o Conferência Nacional das Classes Trabalhadores (Conclat). ${ }^{71}$ As atividades da Conclat fizeram parte do processo que culminaria, em 1983, na fundação da Central Única dos Trabalhadores (CUT).

\section{Considerações finais}

Há uma representativa diversidade de documentos e informações a respeito de Maringá nos arquivos da DOPS, distribuída em pastas temáticas, em relatórios e em fichas individuais. A presente investigação promoveu uma espécie de cartografia da ação da polícia política em um território determinado, no longo período selecionado.

Na linha sincrônica, foi possível aferir como essa vigilância foi exercida em conjunturas específicas, focalizando um agente político coletivo selecionado ou mesmo um conjunto deles. Exemplo foi a conjuntura de 1968, quando

\footnotetext{
${ }^{69}$ Informe 669-PM-PR. Agosto de 1979. Pasta "9ạ. Subdivisão Policial de Maringá".

${ }^{70}$ Informe 754 PM/1979. Pasta “9². Subdivisão Policial de Maringá”.

${ }^{71}$ Relatório "Encontro dos trabalhadores sindicais". 6 de julho de 1981. Pasta “9². SDP Maringá”.
} 
houve uma série de mobilizações, com características próprias e traços comuns, na cidade de Maringá.

A linha diacrônica ofereceu diferentes subsídios. Por um lado, a abordagem demonstrou a vigilância sobre a sucessão de ações de um mesmo agente político, caso do PCB no período anterior a 1964. Por outro lado, também evidenciou a ação da polícia política nas mudanças de conjuntura. No final da década de 1960, havia a focalização dos agrupamentos da esquerda revolucionária, como o PCBR.

Tal documentação enseja várias possibilidades de abordagem. Uma delas é a de encontrar subsídios para estudar a história de instituições e de personagens investigados. Há a incorporação de anexos de documentos que, por motivos de segurança, nem sempre puderam ser preservados pelos agentes políticos. Os apontamentos sistematizados pelos agentes policiais também oferecem subsídios, desde que utilizados com a devida cautela e com a metodologia correta.

Certas afirmações contidas nos relatórios, vistas com distanciamento, podem parecer hiperbólicas ou anedóticas, mas representavam a peculiar forma de interpretar que regia esses agentes. Essa lógica constituía um fato em si mesmo, visto que tinha o potencial de gerar consequências punitivas. Como regra, tais documentos revelam mais o olhar do órgão de vigilância do que a verdade de quem era vigiado.

A cartografia aqui realizada ofereceu um mapa desse amplo campo de possibilidades. Mais do que isso, ao circunscrever a ação da DOPS no marco do território do município, também constituiu um subsídio para narrar sua história política com novos olhares.

Artigo recebido para publicação em 30/05/2016

Artigo aprovado para publicação em 06/02/2017 